\title{
Primarização como Estratégia de Redução de Custos: uma Metodologia para Identificar e Mensurar os Fatores que Suportam a Decisão
}

\section{Insourcing as a Stratagy for Cost Reduction: a Methodology to Identifiy and Mensurate the Supporting Decition Factors}

\author{
Geraldo Magela Ribeiro dos Santos \\ Mestrado em Ciências Contábeis pela FUCAPE Business School \\ Rua Paulo de Vasconcelos, 54. Bairro Jabour, Vitória - ES. CEP 29072-300 \\ geraldo.ribeiro@arcelormittal.com.br \\ Arilton Teixeira \\ PhD. em Economia pela University of Minnessota - USA \\ FUCAPE Business School \\ Av. Fernando Ferrari, 1358. Boa Vista, Vitória - ES. CEP 29075-505 \\ arilton@fucape.br
}

\section{Resumo}

Forçada pela crise de 2008, a indústria siderúrgica nacional teve que rever sua estrutura de custos para se manter competitiva. Dentre as estratégias adotadas, a primarização de serviços foi usada visando à redução de custos e da capacidade ociosa de pessoal e equipamentos advindas da queda nas vendas. Nesse contexto, elaboramos este trabalho que visa quantificar, a partir de um estudo de caso de primarização da manutenção eletromecânica na ArcelorMittal Tubarão (AMT), os resultados desta tomada de decisão. Listamos como principais vantagens da primarização na AMT a redução de $24,41 \%$ nos custos dos serviços de manutenção; a redução no nível de retrabalho e de acidentes com perda de tempo (CPT); o aumento da produtividade e do índice de acerto de paradas programadas. Os fatores que mais contribuíram para a primarização dos serviços foram: acordos coletivos de trabalho das contratadas, nos últimos dez anos, superiores aos das contratantes e a incidência de lucro, taxas de administração e impostos sobre os custos da mão de obra e benefícios com pessoal. Este trabalho também conclui que se os preços dos serviços de terceiros fossem corrigidos apenas pela inflação (INPC), nos últimos dez anos, a primarização dos serviços, sob a ótica de custos, seria inviabilizada.

Palavras-chave: Primarização. Terceirização. Manutenção. Redução de Custos.

\footnotetext{
Abstract

The 2008, market crisis made the national siderurgy industry reconsider its cost structure in order to maintain its competitiveness. Among the adopted strategies, insourcing was used in order to reduce costs and improve its productive capacity from its people and equipments resulting from declining sales. This research has been developed within this context and has as its objective to quantify the results of this choice. In order to achieve this objective, an insourcing case study of mechanical maintenance at ArcelorMittal Tubarão (AMT) was used. Among the main advantages of insourcing at AMT are: the reduction of $24,41 \%$ in maintenance services costs; a reduction in the level of rework and the level of lost time injuries (LTI); increased productivity and the index for available time fulfillment on 
shutdown. The factors that most contributed for the services insourcing are: collective bargaining agreements of the contractors higher than those of contracting and the incidence of profit, management fees (rates administration) and taxes on the cost of labor and benefits to employees. This research also concludes that if the service prices of third parties were only adjusted based upon the inflation index (INPC) over the last ten years, the insourcing of services, if viewed from the costs standpoint, would have been unfeasible.

Keywords: Insourcing. Outsourcing. Maintenance. Reducing Costs.

\section{Introdução}

O mercado siderúrgico mundial e, em especial, a siderurgia brasileira foi diretamente atingido pela crise do subprime americano em setembro de 2008. Segundo o Instituto Aço Brasil - IABr, em dezembro de 2008, as vendas no mercado interno de produtos siderúrgicos caíram $52 \%$ em relação aos níveis médios registrados no período de janeiro a outubro do mesmo ano.

Para sair da crise, a siderurgia nacional adotou como principais estratégias a diversificação de produtos e a integração vertical, em especial investimento na autossuficiência em minério de ferro, um dos principais componentes de custo da siderurgia. Segundo a Revista Valor Investem de Março/2012, os principais "Players" do mercado siderúrgico nacional passaram a priorizar seus investimentos na mineração.

A ArcelorMittal Tubarão (AMT), por não possuir mina própria, teve de buscar alternativas para enfrentar a crise que, no seu caso particular, foi agravada pelo aumento da capacidade de produção de 5 para 7,5 milhões de toneladas/ano de aço no final de 2007.

Uma das iniciativas foi a primarização da manutenção eletromecânica, por envolver um contingente de mais de 700 profissionais e corresponder a $16 \%$ do número de empregados de terceiros que prestam serviço na empresa. Dentre os objetivos da empresa para adotar esta política estavam a redução de custos, evitar perda de know-how e redução da capacidade ociosa.

Partindo deste contexto os objetivos desta pesquisa são: identificar os fatores que levam as empresas a primarizar serviços, quantificar os ganhos e apresentar uma metodologia para mensurar estes ganhos.

Identificamos, a partir da revisão de literatura, vários fatores que levam as empresas a adotar a primarização: Redução de custos (CASTRO; BIM, 2007; MAGALHÃES, 2011; SILVA, 2011; PALMA, 2012); Perda de know-how (AZEVEDO, 1996; PERÚCIA et al., 2011; PALMA, 2012; DRAUZ, 2013); Economia de escala (CASTRO; BIM, 2007; PERÚCIA et al., 2011; DRAUZ, 2013); Redução da Capacidade ociosa (PERÚCIA et al. 2011; DRAUS, 2013); Mitigar riscos à imagem da empresa quanto à responsabilidade social, ambiental e passivos trabalhistas (FIGUEIREDO JÚNIOR, 2007; CASTRO; BIM, 2007; SILVA, 2011); Romper dependência unilateral e mitigar hold-up (AZEVEDO, 1996; FIGUEIREDO JÚNIOR, 2007; PALMA, 2012); Queda na qualidade dos serviços, aumento no índice de acidentes e perdas materiais (CASTRO; BIM, 2007; MAGALHÃES, 2011); Redução da assimetria informacional (AZEVEDO, 1996; FIGUEIREDO JÚNIOR, 2007) e Decisão Judicial.

Utilizando uma Planilha de Composição Analítica de Preços quantificamos uma redução de $24,41 \%$ nos custos de manutenção da AMT, equivalente a $\mathrm{R} \$ 1.293 .681,38$ por mês. 
A importância desta pesquisa é ressaltada pela proposta de utilização da primarização como estratégia de redução de custos, tema que contrapõe a recente onda de terceirização, e apresentação de uma metodologia de cálculo de ganhos.

O objetivo deste trabalho foi desenvolver uma metodologia para identificar e mensurar os fatores que suportam a decisão das empresas de primarizar serviços. Para tanto fez-se uso do estudo de caso, tendo-se desenvolvido as seguintes etapas: análise dos contratos de serviços de terceiros, análise das convenções coletivas de trabalho do pessoal próprio e das Contratadas, entrevistas individuais e conversação livre com os gerentes de manutenção da AMT, apresentação da metodologia de cálculo de ganhos, análise e resultados e, por último, apresentação das considerações finais.

\section{Referencial Teórico}

A ArcelorMittal Tubarão, por produzir commodities tem como estratégia de negócio a Liderança Geral de Custos que, segundo Porter (1986), se baseia na economia de escala, possibilita maior acesso a recursos, redução de custos e controle rígido de despesas.

Outra estratégia da AMT é a Excelência Operacional cujas premissas, segundo Treacy e Wiersema (1995), são: foco na fabricação de grandes volumes de produtos padronizados; gestão forte na utilização de procedimentos operacionais padronizados; disciplina no cumprimento de padrões e trabalho em equipe; aversão ao desperdício; recompensa à eficiência; relacionamento estreito e constante com os fornecedores e clientes; sistemas de informação integrados, confiáveis e de alta velocidade e investimento em atualização tecnológica.

Segundo Hayek (1945), a eficiência de uma empresa é medida pela sua capacidade de reagir às mudanças, e uma delas é o dilema "make or buy" ou a "primarização x terceirização" que será resolvido, pela maioria dos gestores, com base na lógica econômica.

Para Porter (1986), a decisão da primarização “deve extrapolar uma simples análise de custos e investimentos necessários, considerando os problemas estratégicos mais amplos da integração (make) em comparação com o uso de transações de mercado (buy)".

Lindermann e Hansen (2008), conhecendo as dificuldades das empresas de identificar o melhor momento de optar pela primarização ou terceirização de atividades e a partir de um estudo de caso de primarização da manutenção de embarcações, propuseram um modelo de apoio à decisão de primarização ou terceirização que envolve oito perspectivas: econômicocontábil, competências essenciais, custos de transação, estratégica, cultural, trabalhista, relacionamento com a comunidade e ambiental.

A decisão da AMT de primarizar a manutenção teve como foco principal a redução de custos e a utilização da capacidade ociosa de pessoal e equipamentos, porém levou em consideração as perspectivas enumeradas por Lindermann e Hansen (2008).

Visando a um melhor entendimento deste trabalho, introduzimos os conceitos de manutenção, terceirização e primarização.

\subsection{Conceitos de Manutenção, Terceirização e Primarização}

\section{a. Manutenção}

A manutenção é definida como "um conjunto de ações que permitam manter ou restabelecer um bem dentro de um estado específico ou como uma medida para assegurar um determinado serviço" (MIRSHAWKA; OLMEDO, 1993).

$\mathrm{Na}$ ArcelorMittal Tubarão (AMT) a manutenção tem a função estratégica de garantir a estabilidade do processo, a confiabilidade e disponibilidade das unidades operacionais e a maximização da vida útil dos ativos da empresa. 


\section{b. Terceirização}

A contratação de terceiros para a prestação de serviços tem diversas denominações, e as mais comuns são: Outsourcing (BEAUMONT; SOHAL, 2004), Terceirização e Parceria (MARTINS, 2005). Para a maioria dos autores, terceirização é uma estratégia de gestão que visa obter ganho de competitividade, mediante a contratação de empresas especializadas para atuar nas atividades meio para que a contratante possa focar na sua atividade-fim (GIOSA, 2003; QUEIROZ, 2004; LEIRIA, 2006).

A terceirização da execução da manutenção eletromecânica na ArcelorMittal Tubarão (AMT) ocorreu no ano de 2000, e visava à redução de custos e melhoria na flexibilidade operacional. Nessa época, foram contratadas quatro empresas especializadas responsáveis cada uma, pela Manutenção Mecânica, lubrificação, manutenção de estruturas metálicas e manutenção elétrica e de instrumentação. Permaneceram a cargo do efetivo próprio da AMT as atividades de Planejamento, Programação e Controle (PPC) da manutenção, consideradas estratégicas, além da gestão dessas empresas contratadas.

\section{c. Primarização}

A primarização, também conhecida como: desterceirização, verticalização ou integração vertical, insourcing, reverse outsourcing ou re-insourcing (DRAUZ, 2013), caracteriza-se pela reversão da terceirização, isto é, consiste em retomar as atividades que haviam sido terceirizadas (MAGALHÃES et al., 2011). Na primarização, a empresa contratante passa a executar com efetivo próprio as atividades que eram executadas por terceiros de empresas contratadas.

A primarização dos serviços de manutenção, na ArcelorMittal Tubarão (AMT), teve início em 2010 com a implantação de um projeto piloto no Laminador de Tiras a Quente (LTQ) e foi concluído em agosto de 2013. Teve como premissa, mediante acordo com o Ministério Público do Trabalho e o Sindicato dos Empregados, a priorização da contratação dos profissionais das empresas terceirizadas, visando manter a especialização e mitigar riscos sociais.

\section{Metodologia de Cálculo de Ganhos}

Utilizou-se para o cálculo de ganhos uma Planilha Excel, denominada de "Composição Analítica de Preço Mensal”, parte integrante dos contratos de serviços de terceiros da AMT. O objetivo principal da "Composição Analítica de Preço Mensal" foi conhecer o peso de cada recurso no valor dos serviços, permitindo que o realinhamento anual dos preços, já que os prazos dos contratos são em média de três anos, restabeleça o equilíbrio econômico e financeiro do contrato ao corrigir os recursos de acordo com o seu peso e seu indicador de inflação. Descrição dos campos da Planilha com suas respectivas definições e premissas estão disponíveis na dissertação de mestrado (SANTOS, 2014, p.21).

Limitamos este estudo de caso à parcela referente à mão de obra e benefícios com pessoal, por ter maior peso na composição dos custos de manutenção. Portanto, este estudo não contempla custos referentes a ferramentas, equipamentos e veículos nem dos materiais de consumo (gases, eletrodos, discos de corte, fita isolante entre outros) e peças e materiais de reposição (sobressalentes) cujo fornecimento ou reembolso, na maioria dos contratos pesquisados, já era de responsabilidade da AMT.

É objeto de análise na Planilha: a remuneração do pessoal próprio e de terceiros, quantidade de profissionais envolvidos nos serviços (mão de obra direta e indireta), benefícios com pessoal, encargos sociais e trabalhistas e Benefícios e Despesas Indiretas - BDI. 


\subsection{Encargos Sociais e Trabalhistas}

Não existe consenso sobre a definição de encargos sociais tampouco sobre o seu percentual incidente sobre a mão de obra. O estudo do Dieese (2006), intitulado "Encargos Sociais no Brasil: Conceito, Magnitude e Reflexos no Emprego", afirma que pode variar entre $25,2 \%$ e $102,06 \%$, dependendo dos conceitos de salário, encargos sociais e obrigações trabalhistas. Já Pastore (1996) define encargo social como tudo o que a empresa desembolsa e que excede o custo da hora efetivamente trabalhada.

Pesquisa conduzida pela consultoria internacional UHY em 25 países concluiu que o Brasil é o país com o maior encargo social do mundo, chegando a $57,6 \%$ do salário do empregado. Em segundo lugar está a Itália, com 51,84\% e, em terceiro, a França com 42,79\%. A média mundial é de $23 \%$ e, nos Estados Unidos, 8,2\%, e o menor do mundo é o da Dinamarca com $1,4 \%$.

A Tabela 1 demonstra os encargos sociais e trabalhistas adotados neste estudo de caso e que corresponde ao percentual médio praticado nos contratos de manutenção pesquisados.

Tabela 1 - Encargos Sociais e Trabalhistas

\begin{tabular}{|c|c|}
\hline \multicolumn{2}{|l|}{ Encargos Sociais / Trabalhistas } \\
\hline Componentes & Incidência \\
\hline \multicolumn{2}{|l|}{ A) Obrigações Sociais } \\
\hline A.1 INSS & $20,00 \%$ \\
\hline A.2 FGTS & $8,00 \%$ \\
\hline A.3 SESI/SESC & $1,50 \%$ \\
\hline A.4 SENAI/SENAC & $1,00 \%$ \\
\hline A.5 INCRA & $0,20 \%$ \\
\hline A.6 SALÁRIO EDUCAÇÃO & $2,50 \%$ \\
\hline A.7 SEGURO ACIDENTE & $2,00 \%$ \\
\hline A.8 SEBRAE & $0,60 \%$ \\
\hline Soma "A" & $36,80 \%$ \\
\hline \multicolumn{2}{|l|}{ B) Encargos que Recebem Incidência de "A" } \\
\hline B.1 FÉRIAS (26/275 Dias) & $9,45 \%$ \\
\hline B.2 ABONO DE FÉRIAS (10/275 Dias) & $3,64 \%$ \\
\hline B.3 AUX. ENFERMIDADE/FALTAS JUST. (13/275 Dias) & $4,73 \%$ \\
\hline B.4 AVISO PRÉVIO (10/275 Dias) & $3,64 \%$ \\
\hline Soma "B" & $21,46 \%$ \\
\hline \multicolumn{2}{|l|}{ C) Encargos que não Recebem Encargos de "A" } \\
\hline C. $113^{\circ}$ SALÁRIO (30/275 Dias) & $10,91 \%$ \\
\hline C. 2 DESPESA DE RESCISÃO CONTRATUAL & $2,06 \%$ \\
\hline Soma "C" & $12,97 \%$ \\
\hline \multicolumn{2}{|l|}{ D) Taxa de Reincidência } \\
\hline D.1 SOMA DE “A”SOBRE SOMA DE “B” & $7,90 \%$ \\
\hline D. 2 INCIDÊNCIA DO FGTS SOBRE O $13^{\circ}$ SALÁRIO & $0,87 \%$ \\
\hline Soma "D" & $8,77 \%$ \\
\hline Total = "A"+"B"+"C"+"D" & $80,00 \%$ \\
\hline
\end{tabular}

\subsection{Benefícios e Despesas Indiretas - BDI}

Budget Difference Income (BDI) traduzido por Benefícios ou Bônus e Despesas Indiretas é definido na Cartilha de BDI do Conselho Regional de Engenharia e Arquitetura do Espírito Santo (CREA-ES) como: "a parte do preço de cada serviço, expresso em percentual, que não se designa ao custo direto ou que não está efetivamente identificado como a produção direta do serviço ou produto". Em geral, o BDI é composto por lucro, despesas financeiras, rateio do custo da administração central e/ou local e impostos sobre o faturamento.

Também não existe consenso sobre o método de cálculo do BDI, tampouco sobre os itens que o compõem ou ainda se incide sobre os custos ou sobre o faturamento. Existe ainda Santos, G. M. R.; Teixeira, A. 
a forma hibrida em que os impostos incidem sobre o faturamento, e os demais componentes do BDI, sobre os custos. Nesta pesquisa, optamos pela incidência do BDI sobre os custos, além de considerar o lucro real como regime contábil.

$\mathrm{Na}$ prática, o BDI reflete a estratégia das empresas na comercialização dos seus serviços, ou seja, esse percentual pode ser alterado de acordo com o interesse da empresa em ganhar determinado contrato, pois parte-se do princípio de que os demais custos são similares para todos os proponentes.

Na Tabela 2, detalhamos os principais componentes do BDI, que totaliza 29,10\% sobre o faturamento ou $41,04 \%$ sobre os custos. O percentual de BDI adotado neste estudo corresponde aos valores médios praticados nos contratos de manutenção pesquisados.

Abaixo, detalhamento do BDI utilizado em nossas planilhas de cálculo.

Tabela 2 - BDI (Benefícios e Despesas Indiretas)

\begin{tabular}{ll}
\hline \multicolumn{2}{c}{ BDI (Benefícios e Despesas Indiretas) } \\
\hline Administração Central & $4,80 \%$ \\
Lucro & $7,50 \%$ \\
IR / CSLL & $2,55 \%$ \\
PIS & $1,65 \%$ \\
COFINS & $7,60 \%$ \\
ISS & $5,00 \%$ \\
Total & $\mathbf{2 9 , 1 0 \%}$ \\
Fator multiplicador & $\mathbf{4 1 , 0 4 3 7 2 4 \%}$ \\
& \\
& \multicolumn{1}{|l}{ Alíquota } \\
\hline IR = Imposto de Renda & $25 \%$ Sobre o Lucro \\
CSLL = Contribuição Sobre o Lucro Líquido & $9 \%$ Sobre o Lucro \\
PIS = Programa de Integração Social & $1,65 \%$ Sobre o Valor da NF \\
COFINS = Contribuição Para Financiamento da Seguridade Social & $7,60 \%$ Sobre o Valor da NF \\
ISS = Imposto Sobre Serviço de Qualquer Natureza & $5 \%$ Sobre o Valor da NF \\
\hline
\end{tabular}

\section{Análise e Resultados}

Neste trabalho, comparamos os desembolsos mensais da manutenção eletromecânica primarizada com a terceirizada em três cenários diferentes. No primeiro, apresentamos a economia obtida com a primarização da manutenção em 2013 (Tabela 3). No segundo cenário, analisamos os ganhos obtidos pela AMT com a terceirização dos serviços de manutenção no ano de 2000 (Tabela 4).

Já no terceiro cenário, corrigimos os preços de serviços de terceiros (Tabela 4), apenas pela inflação (INPC $=95,8 \%$ ) do período entre 01/11/2002 e 31/10/2013, conforme Tabela 5 . A escolha do Índice Nacional de Preços ao Consumidor (INPC) da FGV se deve à sua utilização para reposição das perdas salariais, durante as negociações do Acordo Coletivo dos empregados metalúrgicos que ocorrem no mês de Novembro de cada ano, por ser a data base da categoria. A correção permite avaliar se a primarização seria viável caso os preços dos serviços de terceiros fossem realinhados apenas pela inflação no período.

Finalmente, comparamos a manutenção eletromecânica terceirizada, base 2013, no valor de $\mathrm{R}$ \$ 5.299.335,72 (Tabela 3) com o valor da terceirização, também no ano base 2013, porém corrigido pelo INPC, sendo este valor igual a R\$ 3.195.243,54 (Tabela 5). Desta forma, identificamos que os fatores que mais contribuíram para inviabilizar a continuidade da terceirização da manutenção eletromecânica na AMT foram os salários e benefícios de terceiros que cresceram acima da inflação. 


\subsection{Comparação entre os Custos da Manutenção Eletromecânica Primarizada com Terceirizada (Valores Base Novembro/2013)}

A Tabela 3 compara os custos da Manutenção executada pelo pessoal da ArcelorMittal Tubarão - Coluna Primarização, com os valores pagos às Contratadas - Coluna Terceirização.

Analisando a Tabela 3, concluímos que com a primarização:

1) A média dos salários mensais dos empregados da ArcelorMittal Tubarão é de R\$ 2.822,33 (linha 3 PREÇO UNIT.) contra R \$ 2.478,21 das Contratadas, portanto 13,89\% superior ao das Contratadas;

2) Os benefícios com pessoal da ArcelorMittal Tubarão (linha 4 PREÇO UNIT.) de R \$ 1.947,27 são, em média, 134,26\% superiores aos benefícios das Contratadas que são de $\mathrm{R} \$ 831,24$. Tal diferença é explicada por benefícios diferenciados da AMT, tais como: planos de saúde e odontológico extensivo aos familiares, remédios subsidiados em $75 \%$, medicina ocupacional e preventiva, seguro de vida extensivo ao cônjuge, auxílio funerária, previdência privada, participação nos lucros em média de 3,5 salários por ano, alimentação, transporte, treinamentos, mais $2 / 3$ do salário quando do retorno de férias;

3) Se comparado o efetivo de terceiros de 710 profissionais (linha 4 QTD. TERCEIRIZAÇÃO), com os 570 profissionais (linha 4 QTD. PRIMARIZAÇÃO) que foram primarizados, houve uma redução de $20 \%$ no efetivo total da manutenção, a título de produtividade conforme premissa do estudo de viabilidade deste projeto. Esse ganho de produtividade deve-se a: maior rigor no recrutamento e seleção de profissionais; treinamento e qualificação da mão de obra; utilização do pessoal próprio que fazia a gestão das Contratadas no planejamento e programação de serviços que passou a focar a especialização das tarefas; redução de absenteísmo e retrabalho; ênfase na melhoria dos processos e apoio da engenharia de manutenção no desenvolvimento de dispositivos que permitam ganhos de produtividade e de segurança na execução de tarefas repetitivas; simplificação na liberação das frentes de serviço, análise preliminar de risco e logística de pessoal, equipamento e material.

4) Houve uma redução de custos de $24,41 \%$ equivalente a $\mathrm{R} \$ 1.293 .681,38$ por mês (Linha 12 DIFERENÇA), ou seja, o custo mensal da primarização da manutenção é de $\mathrm{R} \$$ 4.005.654,34 contra R 5 5.299.335,72 da terceirização, conforme linha 12 "SUBTOTAIS" da Planilha.

\subsection{Terceirização da Manutenção em 2000}

Com o objetivo de identificar os fatores que mais contribuíram para a primarização da manutenção na AMT, este estudo nos levou a avaliar os custos da terceirização da manutenção eletromecânica que ocorreu na AMT em 2000. Devido à indisponibilidade da Convenção Coletiva de Trabalho (CCT) de 2000, no site do Sindimetal, adotamos para nossos cálculos a CCT de 2003, ou seja, os valores são base Novembro de 2003, com os salários e benefícios corrigidos pela Convenção Coletiva de Trabalho (CCT 2003/2004 Sindifer x Sindimetal).

A CCT 2003/2004 estabelecia o piso salarial de R $\$ 1.037,18$ para os empregados da AMT e de $\mathrm{R} \$ 335,00$ para os empregados das terceirizadas, ao passo que o salário mínimo era de R \$ 240,00. Os benefícios dos empregados da ArcelorMittal Tubarão (AMT) tais como: planos de saúde e odontológico, remédios, medicina ocupacional e preventiva, seguro de vida, previdência privada, participação nos lucros, uniformes e EPI's, alimentação, transporte, treinamentos, mais $2 / 3$ de férias entre outros, correspondiam a mais de $100 \%$ do piso salarial, enquanto nas empresas terceirizadas esses benefícios eram basicamente uniformes e EPI's, transporte e seguro de vida. 
Tabela 3 - Comparativa de Custos de Manutenção Primarizada x Terceirizada - Base 2013

\begin{tabular}{|c|c|c|c|c|c|c|c|c|c|c|}
\hline \multirow{5}{*}{$\stackrel{\widetilde{J}}{\leftrightarrows}$} & \multicolumn{10}{|c|}{ Composição Analítica de Preço Mensal - Comparativo Primarização x Terceirização } \\
\hline & \multicolumn{10}{|c|}{ Serviços de Manutenção Eletromecânica } \\
\hline & \multicolumn{10}{|c|}{ Base de Preços Novembro de 2013 - Com BDI Detalhado } \\
\hline & & & \multicolumn{3}{|c|}{ Primarização } & \multicolumn{3}{|c|}{ Terceirização } & \multicolumn{2}{|c|}{ Diferença } \\
\hline & Categorias Profissionais & Unid. & QTD. & Preço Unit. & Subtotais & QTD. & Preço Unit. & Subtotais & $\%$ & Valores (R\$) \\
\hline 1 & Total Mão e Obra Direta (MOD) & H/Mês & 484 & $\mathrm{R} \$ 2.682,42$ & $\mathrm{R} \$ 1.298 .290,68$ & 602 & $\mathrm{R} \$ 2.305,96$ & $\mathrm{R} \$ 1.388 .188,04$ & $16,33 \%$ & $-\mathrm{R} \$ 89.897,36$ \\
\hline 2 & Total Mão e Obra Indireta (MOI) & H/Mês & 86 & $\mathrm{R} \$ 3.609,74$ & $\mathrm{R} \$ 310.437,95$ & 108 & $\mathrm{R} \$ 2.594,72$ & $\mathrm{R} \$ 371.340,30$ & $39,12 \%$ & $-\mathrm{R} \$ 60.902,35$ \\
\hline \multirow[t]{3}{*}{4} & Total Benefícios com Pessoal & H/Mês & 570 & $\mathrm{R} \$ 1.947,27$ & $\mathrm{R} \$ 1.109 .942,81$ & 710 & $\mathrm{R} \$ 831,24$ & $\mathrm{R} \$ 590.177,21$ & $134,26 \%$ & $-\mathrm{R} \$ 519.765,61$ \\
\hline & \multicolumn{10}{|c|}{ Resumo } \\
\hline & Descrição & & \multicolumn{2}{|c|}{ Particip. (\%) } & Valores $(\mathbf{R} \$)$ & \multicolumn{2}{|r|}{ Particip. (\%) } & \multicolumn{2}{|l|}{ Valores $(\mathbf{R} \$)$} & \\
\hline 5 & Mão de Obra Direta e Indireta & & 570 & $40,16 \%$ & $\mathrm{R} \$ 1.608 .728,63$ & 710 & $46,83 \%$ & $\mathrm{R} \$ 1.759 .528,34$ & $-8,57 \%$ & $-\mathrm{R} \$ 150.799,71$ \\
\hline 6 & Encargos Sociais/Trabalhistas & & $80,00 \%$ & $32,13 \%$ & $\mathrm{R} \$ 1.286 .982,90$ & $80,00 \%$ & $37,46 \%$ & $\mathrm{R} \$ 1.407 .622,67$ & $-8,57 \%$ & $-\mathrm{R} \$ 120.639,77$ \\
\hline 11 & ISS + IRPJ/CSSL & & $0,00 \%$ & & 0,00 & & $10,65 \%$ & $\mathrm{R} \$ 400.155,46$ & & $-\mathrm{R} \$ 400.155,46$ \\
\hline 12 & Total Mensal & & & & $\mathrm{R} \$ 4.005 .654,34$ & & & $\mathrm{R} \$ 5.299 .335,72$ & $-24,41 \%$ & $-\mathrm{R} \$ 1.293 .681,38$ \\
\hline 13 & Preço Homem/Mês & & & & $\mathrm{R} \$ 8.276,15$ & & & $\mathrm{R} \$ 8.802,88$ & $-5,98 \%$ & $-\mathrm{R} \$ 526,74$ \\
\hline 14 & Preço Homem/Hora & & & & $\mathrm{R} \$ 50,46$ & & & $\mathrm{R} \$ 53,68$ & $-5,98 \%$ & $-\mathrm{R} \$ 3,21$ \\
\hline
\end{tabular}


A Tabela 4, a seguir, manteve os mesmos parâmetros adotados na avaliação da primarização no que se refere a efetivo de pessoal, percentuais de encargos sociais e BDI, exceto salários que são base 2003.

Evidenciamos que a avaliação acima pode ser considerada conservadora pelos seguintes motivos: a) foi utilizado o piso salarial da Convenção Coletiva de Trabalho CST x SINDIMETAL, quando na política salarial da CST praticava-se o terceiro quartil devido à especialização dos seus profissionais e tempo de casa em média de 15 anos de empresa, ou seja, aumento no salário de $1 \%$ para cada ano de serviço; b) aumentado em $50 \%$ o piso salarial de terceiros, por tratar-se de mão de obra qualificada e acrescida de insalubridade, passando o salário de mecânicos e lubrificadores para $\mathrm{R} \$ 600,00$ por mês; c) Os salários de supervisores e instrumentistas/eletricistas seguiram a mesma proporção.

Na Tabela 4, linha 12 "DIFERENÇA", temos que a redução de custo mensal com a terceirização foi de R $\$ 228.962,51$ ou $14,03 \%$, devido a salários e benefícios com pessoal próprio serem, respectivamente, 56,97\% (linha 3 "DIFERENÇA") e 324,28\% (linha 4 "DIFERENÇA") superiores aos dos empregados das Contratadas.

\subsection{Correção dos Valores da Tabela 4, Referência 2003, pelo INPC e Comparação com a Tabela 3 Referência 2013}

Visando avaliar se os custos da terceirização da manutenção permaneceriam competitivos se corrigidos apenas pela inflação, fizemos a correção dos valores da Tabela 4, no período de 01/11/2002 a 31/10/2013, pelo Índice Nacional de Preços ao Consumidor (INPC), que nesse período teve uma variação de 95,8249\%. A escolha do INPC se deve ao seu uso, nos acordos coletivos de trabalho, como indexador de salários.

A Tabela 5 mostra que, se corrigidos apenas pela inflação do período (INPC $=95,8 \%$ ) o custo da primarização seria de $R$ \$ 3.643.609,15, contra $R$ \$ 3.195.243,54 da terceirização (linha 12 "SUBTOTAIS"), portanto valeria a pena manter a terceirização, pois os preços dos serviços de terceiros seriam $14,03 \%$ ou $\mathrm{R} \$ 448.365,61$ por mês inferiores aos da primarização. 
Tabela 4 - Comparativo Manutenção Terceirizada x Primarizada Base 2003

\begin{tabular}{|c|c|c|c|c|c|c|c|c|c|c|}
\hline \multirow{5}{*}{ 祍 } & \multicolumn{10}{|c|}{ Composição Analítica de Preço Mensal - Comparativo Pimarização x Terceirização } \\
\hline & \multicolumn{10}{|c|}{ Serviços e Manutenção Eletromecânica } \\
\hline & \multicolumn{10}{|c|}{ Base de Preços Novembro de 2003-Com BDI Detalhado } \\
\hline & \multicolumn{2}{|l|}{ Mão de Obra Direta (MOD) } & \multicolumn{3}{|c|}{ Primarização } & \multicolumn{3}{|c|}{ Terceirização } & \multicolumn{2}{|c|}{ Diferença } \\
\hline & Categorias Profissionais & Unid. & Qtd. & Preço Unit. & Subtotais & Qtd. & Preço Unit. & Subtotais & $\%$ & Valores $(\mathrm{R} \$)$ \\
\hline 1 & Total Mão e Obra Direta (MOD) & H/Mês & 484 & $\mathrm{R} \$ 1.121,55$ & $\mathrm{R} \$ 542.828,00$ & 602 & $\mathrm{R} \$ 715,55$ & $\mathrm{R} \$ 430.760,00$ & $56,74 \%$ & $\mathrm{R} \$ 112.068,00$ \\
\hline 2 & Total Mão e Obra Indireta (MOI) & H/Mês & 86 & $\mathrm{R} \$ 1.577,99$ & $\mathrm{R} \$ 135.707,00$ & 108 & $\mathrm{R} \$ 997,13$ & $\mathrm{R} \$ 107.690,00$ & $58,25 \%$ & $\mathrm{R} \$ 28.017,00$ \\
\hline \multirow{2}{*}{4} & \multicolumn{10}{|c|}{ Resumo } \\
\hline & Descrição & & \multicolumn{2}{|c|}{ Particip. (\%) } & Valores (R\$) & \multicolumn{2}{|c|}{ Particip. (\%) } & \multicolumn{2}{|l|}{ Valores (R\$) } & \\
\hline 5 & Mão e Obra Direta e Indireta & & 570 & $36,47 \%$ & $\mathrm{R} \$ 378.535,00$ & 710 & $46,54 \%$ & $\mathrm{R} \$ 538.450,00$ & $26,02 \%$ & $\mathrm{R} \$ 140.085,00$ \\
\hline 6 & Encargos Sociais/Trabalhistas & & $80,00 \%$ & $29,17 \%$ & $\mathrm{R} \$ 542.828,00$ & $80,00 \%$ & $37,23 \%$ & $\mathrm{R} \$ 430.760,00$ & $26,02 \%$ & $\mathrm{R} \$ 112.068,00$ \\
\hline 7 & Benefícios com Pessoal & & & $34,36 \%$ & $\mathrm{R} \$ 639.283,50$ & & $16,22 \%$ & $\mathrm{R} \$ 187.684,49$ & $240,62 \%$ & $\mathrm{R} \$ 451.599,01$ \\
\hline 8 & Subtotal & & & $100,00 \%$ & $\mathrm{R} \$ 1.860 .646,50$ & & $100,00 \%$ & $\mathrm{R} \$ 1.156 .894,49$ & $60,83 \%$ & $\mathrm{R} \$ 703.752,01$ \\
\hline 12 & Total Mensal & & & & $\mathrm{R} \$ 1.860 .646,50$ & & & $\mathrm{R} \$ 1.631 .683,99$ & $14,03 \%$ & $\mathrm{R} \$ 228.962,51$ \\
\hline 13 & Preço Homem/Mês & & & & $\mathrm{R} \$ 3.844,31$ & & & $\mathrm{R} \$ 2.710,44$ & $41,83 \%$ & $\mathrm{R} \$ 1.133,87$ \\
\hline 14 & Preço Homem/Hora & & & & $\mathrm{R} \$ 23,44$ & & & $\mathrm{R} \$ 16,53$ & $41,83 \%$ & $\mathrm{R} \$ 6,91$ \\
\hline
\end{tabular}


Tabela 5 - Comparativo Manutenção Terceirizada x Primarizada Base 2003, Corrigido pelo INPC

\begin{tabular}{|c|c|c|c|c|c|c|c|c|c|c|}
\hline \multirow{5}{*}{ 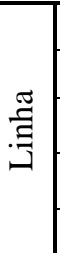 } & \multicolumn{10}{|c|}{ Composição Analítica de Preço Mensal - Comparativo Primarização x Terceirização } \\
\hline & \multicolumn{10}{|c|}{ Serviços de Manutenção Eletromecânica } \\
\hline & \multicolumn{10}{|c|}{ Preços Atualizados Pelo INPC de 01/11/2002 até 30/10/2013 (95,8249\%) - Com BDI Detalhado } \\
\hline & \multicolumn{2}{|l|}{ Mão de Obra Direta (MOD) } & \multicolumn{3}{|c|}{ Primarização } & \multicolumn{3}{|c|}{ Terceirização } & \multicolumn{2}{|c|}{ Diferença } \\
\hline & Categorias Profissionais & Unid. & Qtd. & Preço Unit. & Subtotais & Qtd. & Preço Unit. & Subtotais & $\%$ & Valores $(\mathrm{R} \$)$ \\
\hline 1 & Total Mão de Obra Direta (MOD) & H/Mês & 484 & $\mathrm{R} \$ 2.196,27$ & $\mathrm{R} \$ 1.062 .992,39$ & 602 & $\mathrm{R} \$ 1.401,22$ & $\mathrm{R} \$ 843.535,34$ & $56,74 \%$ & $\mathrm{R} \$ 219.457,05$ \\
\hline 2 & Total Mão de Obra Indireta (MOI) & H/Mês & 86 & $\mathrm{R} \$ 3.090,09$ & $\mathrm{R} \$ 265.748,10$ & 108 & $\mathrm{R} \$ 1.952,63$ & $\mathrm{R} \$ 210.883,83$ & $58,25 \%$ & $\mathrm{R} \$ 54.864,26$ \\
\hline 3 & Total Mão de Obra (MOI + MOD) & H/Mês & 570 & $\mathrm{R} \$ 2.331,12$ & $\mathrm{R} \$ 1.328 .740,49$ & 710 & $\mathrm{R} \$ 1.485,10$ & $\mathrm{R} \$ 1.054 .419,17$ & $56,97 \%$ & $\mathrm{R} \$ 274.321,31$ \\
\hline \multirow[t]{3}{*}{4} & Total Benefícios Com Pessoal & H/Mês & 570 & $\mathrm{R} \$ 2.196,27$ & $\mathrm{R} \$ 1.251 .876,27$ & 710 & $\mathrm{R} \$ 517,65$ & $\mathrm{R} \$ 367.532,96$ & $324,28 \%$ & $\mathrm{R} \$ 884.343,31$ \\
\hline & \multicolumn{10}{|c|}{ Resumo } \\
\hline & Descrição & & & Particip. (\%) & Valores $(\mathrm{R} \$)$ & & Particip. (\%) & Valores $(\mathrm{R} \$)$ & & \\
\hline 5 & Mão de Obra Direta e Indireta & & 570 & $36,47 \%$ & $\mathrm{R} \$ 1.328 .740,49$ & 710 & $46,54 \%$ & $\mathrm{R} \$ 1.054 .419,17$ & $26,02 \%$ & $\mathrm{R} \$ 274.321,31$ \\
\hline 6 & Encargos Sociais/Trabalhistas & & $80,00 \%$ & $29,17 \%$ & $\mathrm{R} \$ 1.062 .992,39$ & $80,00 \%$ & $37,23 \%$ & $\mathrm{R} \$ 843.535,34$ & $26,02 \%$ & $\mathrm{R} \$ 219.457,05$ \\
\hline 7 & Benefícios com Pessoal & & & $34,36 \%$ & $\mathrm{R} \$ 1.251 .876,27$ & & $16,22 \%$ & $\mathrm{R} \$ 367.532,96$ & $240,62 \%$ & $\mathrm{R} \$ 884.343,31$ \\
\hline 8 & Subtotal & & & $100,00 \%$ & $\mathrm{R} \$ 3.643 .609,15$ & & $100,00 \%$ & $\mathrm{R} \$ 2.265 .487,48$ & $60,83 \%$ & $\mathrm{R} \$ 1.378 .121,67$ \\
\hline 9 & Administração Central e Lucro & & $0,00 \%$ & & & $41,04 \%$ & $17,35 \%$ & $\mathrm{R} \$ 393.062,08$ & & $-\mathrm{R} \$ 393.062,08$ \\
\hline 10 & PIS + COFINS & & $0,00 \%$ & & & & $13,04 \%$ & $\mathrm{R} \$ 295.419,57$ & & $-\mathrm{R} \$ 295.419,57$ \\
\hline 11 & ISS + IRPJ/CSSL & & $0,00 \%$ & & & & $10,65 \%$ & $\mathrm{R} \$ 241.274,42$ & & $-\mathrm{R} \$ 241.274,42$ \\
\hline 12 & Total Mensal & & & & $\mathrm{R} \$ 3.643 .609,15$ & & & $\mathrm{R} \$ 3.195 .243,54$ & $14,03 \%$ & $\mathrm{R} \$ 448.365,61$ \\
\hline 13 & Preço Homem/Mês & & & & $\mathrm{R} \$ 7.528,12$ & & & $\mathrm{R} \$ 5.307,71$ & $41,83 \%$ & $\mathrm{R} \$ 2.220,40$ \\
\hline 14 & Preço Homem/Hora & & & & $\mathrm{R} \$ 45,90$ & & & $\mathrm{R} \$ 32,36$ & $41,83 \%$ & $\mathrm{R} \$ 13,54$ \\
\hline
\end{tabular}




\subsection{Fatores que Contribuíram para Inviabilizar a Terceirização}

Identificamos como principal fator de aumento dos custos da terceirização a estratégia de negociação sindical, nos últimos dez anos, de ganhos reais de salários e de benefícios com pessoal, o que permitiu a equiparação dos salários do pessoal próprio com os das Contratadas, bem como a obtenção de benefícios similares conforme exemplificado abaixo.

A título de exemplo, em 2003, o piso salarial dos empregados da ArcelorMittal Tubarão (AMT) era de R $\$ 1.037,18$, ou seja, 3,1 vezes superior ao dos terceiros, que era de $\mathrm{R} \$ 335,00$ (conforme cláusula quinta letra "e" da Convenção Coletiva de Trabalho (CCT) 2003/2004 do Sindifer x Sindimetal) e 4,32 vezes superior ao salário mínimo, que era de R\$ 240,00 em 01.04.2003. Já em 2013, essa relação passou para 1,08, no caso dos terceiros, e 2,31 no salário mínimo, ou seja, piso salarial AMT de R \$ 1.674,83 (CCT 2013/2014) contra $\mathrm{R} \$ 1.552,80$ (conforme CCT 2013/2014 cláusula $6^{\mathrm{a}}$ - piso profissional grupo III para empresas com mais de 500 empregados) e salário mínimo de $\mathrm{R} \$ 724,00$ em 01.01.2014.

Enquanto o piso salarial da AMT aumentou $61,48 \%$, nos últimos dez anos, passando de $\mathrm{R} \$ 1.037,18$ em 2003 para $\mathrm{R} \$ 1.674,83$ em 2013, o salário mínimo aumentou 201,67\%, passando de R \$240,00 em 2003 para $\mathrm{R} \$ 724,00$ em Janeiro/2014. Já o piso salarial das Contratadas aumentou 178,53\%, nos últimos dez anos, passando de R $\$ 335,00$ em 2003 para $\mathrm{R} \$$ 933,06 (Piso salarial de ingresso) em 2013. Porém, se comparado com o piso profissional, que é praticado pelas Contratadas dentro do site AMT, o aumento é de 363,52\%, ou seja, passou de $\mathrm{R} \$ 335,00$ para $\mathrm{R} \$ 1.552,80$. Enquanto isso, a variação do INPC nesse período foi de $95,82 \%$, do IPCA de $93,91 \%$ e do IGPM $=115,00 \%$.

Os principais motivos para a redução da diferença entre os salários do pessoal próprio e os das Contratadas foram: 1) a exigência contratual pela AMT de profissionais com segundo grau completo e/ou curso técnico; 2) incentivo e premiação a profissionais com certificação PNQC - Programa Nacional de Qualificação e Certificação de Pessoal na Área de Manutenção, desenvolvido pela ABRAMAN, em parceria com o SENAI; 3) aumento do salário mínimo bem acima do INPC, forçando também o aumento do piso salarial da categoria na mesma proporção; 4) obtenção de benefícios adicionais tais como: cesta básica ou ticket alimentação, planos de saúde e odontológico, seguro de vida, creche, participação nos lucros, entre outros.

O Gráfico 1 mostra que no período de 2000 a 2013 os empregados da AMT tiveram seus salários reajustados pela CCT em 157\%, contra 191\% das Contratadas (SINDIFER). Já a evolução do INPC no mesmo período foi de $146 \%$, contra um aumento do salário mínimo de $399 \%$. Como o impacto dos salários no custo de serviços de terceiros, em média, é da ordem de $70 \%$, os ganhos reais de salário e benefícios sociais contribuíram para reduzir a diferença entre os custos de execução dos serviços de manutenção com pessoal próprio e com terceiros. 


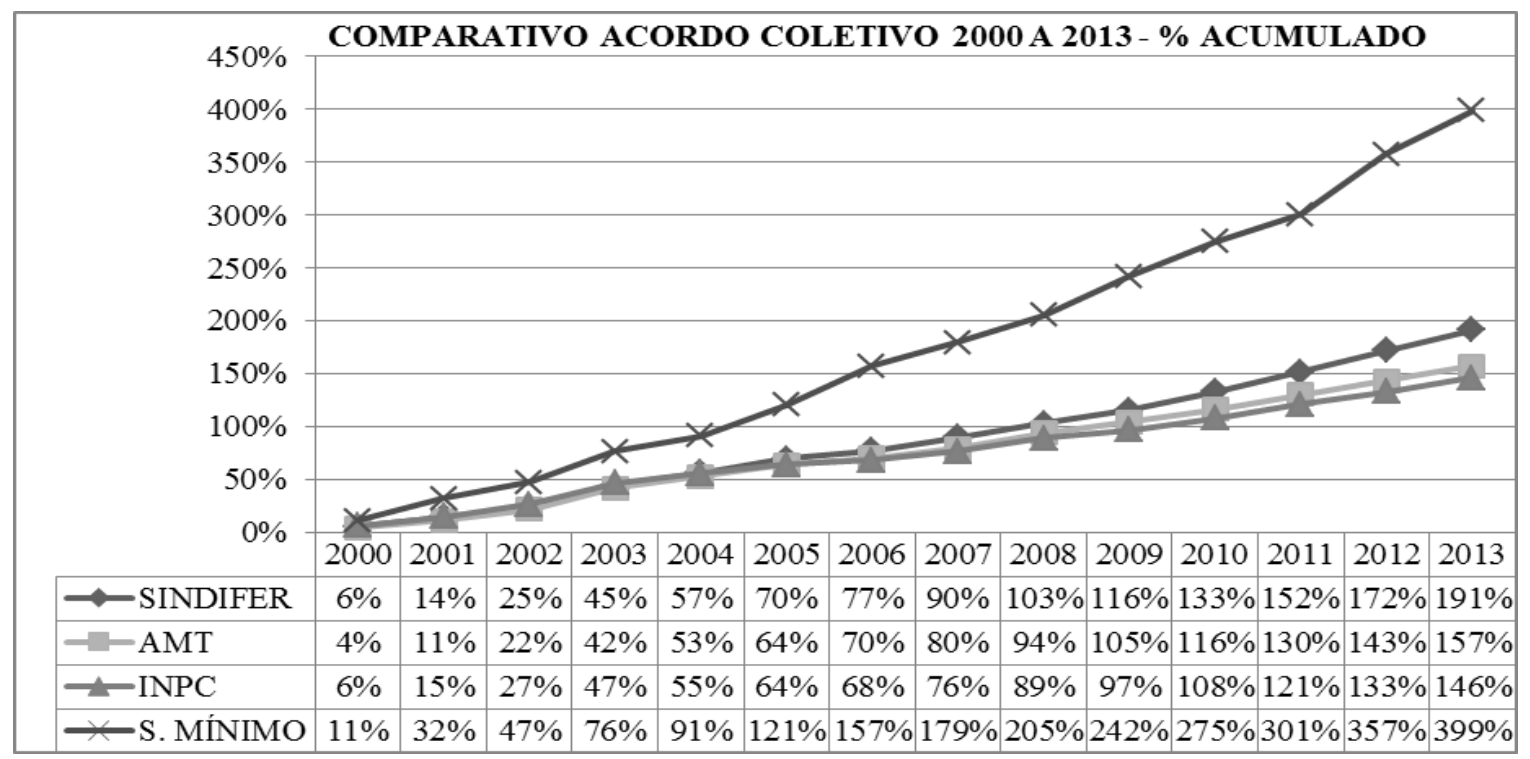

Gráfico 1: Comparativo Acordo coletivo acumulado entre os anos de 2000 a 2013

Nota. Fonte: SINDIMETAL-ES, SINDIFER- ES e FIPE-FGV.

A utilização, pela AMT, do Total Cost by Ownership - TCO (ELLRAM; SIFER, 1998), durante o estudo de viabilidade da primarização da manutenção, permitiu identificar custos inerentes ao processo de terceirização que oneravam a manutenção tais como: custos com pessoal próprio para gestão dos contratos; acordo coletivo das terceirizadas (SINDIFER) com ganhos reais de salário superior ao do pessoal próprio (AMT), conforme Gráfico 1; redução da diferença entre o piso salarial do pessoal próprio e do terceirizado; aposentadoria de profissionais com salários mais altos e substituição por pessoal mais novo e com salário menor; aumento nos custos da mão de obra indireta de terceiros (gerentes, engenheiros de campo, pessoal de planejamento, logística, saúde e segurança do trabalho, conservação e limpeza e segurança patrimonial dos canteiros das Contratadas) nos mesmos percentuais da mão de obra direta.

Além disso, a aplicação do TCO constatou ocorrência de redundância, ou seja, cada uma das quatro empresas que atuavam na manutenção tinha seu efetivo próprio para as atividades de planejamento, saúde e segurança, recursos humanos, logística e outros (pessoal indireto) que correspondia em média a $25 \%$ do custo do pessoal de execução (mão de obra direta).

\subsection{Outros Efeitos da Primarização}

Além da redução no custo dos serviços de manutenção eletromecânica e da mitigação de risco de passivos trabalhistas, a primarização na ArcelorMittal Tubarão (AMT) trouxe outros efeitos que, embora não sejam o foco do nosso trabalho, vamos citá-los aqui para guiar futuras pesquisas.

Em Janeiro de 2014, a Gerência Geral de Manutenção apresentou para a diretoria da AMT o seguinte resultado da primarização: Redução da rotatividade de pessoal em $75 \%$; Redução do absenteísmo de 4,73\% para menos de 1\%; Redução dos acidentes com perda de tempo (CPT) em 55\%; Aumento da produtividade em 28\%, ou seja, de cada 100h programadas para executar uma determinada carteira de serviços, as contratadas gastavam em média $121 \mathrm{~h}$ enquanto as equipes primarizadas executam essa mesma carteira em média com 93h; Redução de Retrabalho; Criação de árvore de carreira dentro da empresa; Profissionais focados em melhorias de processo (planejamento, tempos e métodos, desenvolvimento de ferramentas) e suporte aos Supervisores; Programa de Desenvolvimento Técnico Aplicado (PDTA) para os executores.

Santos, G. M. R.; Teixeira, A. 
Também, com a primarização da manutenção, houve uma melhora significativa nos índices de acerto de Paradas Programadas que impactam diretamente o faturamento da AMT. Por exemplo, uma hora de atraso no retorno de um Alto Forno provoca uma perda de faturamento da ordem de duzentos e cinquenta mil dólares por hora.

Autores como Lindermann e Hansen (2008), Magalhães et al. (2011), Silva (2011), Palma (2012) e Drauz (2013) também citam tais fatores como vantagens da primarização.

Outros efeitos da primarização na ArcelorMittal Tubarão (AMT) foram: Redução na arrecadação de impostos, em especial o ISS dos municípios; Redução na cadeia de fornecedores, pois as empresas contratadas compravam materiais (uniformes, EPI's, materiais de consumo, etc.) e serviços (transporte de pessoal e equipamentos, serviços médicos, segurança do trabalho e patrimonial, entre outros) de empresas próximas ao local de prestação dos serviços; Redução de postos de trabalho, em especial mão de obra indireta que praticamente não foi reaproveitada na primarização.

Citamos como prováveis fragilidades da primarização na AMT: uma menor flexibilidade e agilidade na reposição de pessoal; menor sinergia de boas práticas com outras empresas, tendo em vista que as Contratadas prestam serviços a diferentes clientes o que permite o compartilhamento das melhores práticas; surgimento de custos não previstos como logística de pessoal em hora extra e distribuição de equipamentos e ferramentas em toda a Usina. A ausência de um enforcement contratual, por exemplo, multas em caso de retrabalho ou perdas materiais provocadas pelo efetivo próprio, favorece o corporativismo.

Autores como (LINDERMANN; HANSEN, 2008; MAGALHÃES et al., 2011; SILVA, 2011) também identificaram estes fatores em seus trabalhos.

\section{Considerações Finais}

Os resultados obtidos nesta pesquisa sugerem evidência de que a primarização pode ser utilizada como estratégia de redução de custos. No caso da AMT, a primarização trouxe uma redução de custos de $24,41 \%$ equivalente a $\mathrm{R} \$ 1.293 .681,38$ por mês (Tabela 3), ganho bruto, portanto não contempla eventuais incidências de tributos que serão apurados na escrituração contábil.

Interessante notar que os salários da equipe primarizada são em média 13,89\% superiores aos dos terceirizados, e os benefícios com pessoal, 134,26\%, conforme Tabela 3. Em 2000, ano em que ocorreu a terceirização, essa diferença era respectivamente de 56,97\% para salários e $324,28 \%$ para benefícios com pessoal (vide Tabela 4). As principais explicações para a diferença entre salários e benefícios de pessoal próprio e de terceiros nos últimos dez anos são: acordos coletivos com ganhos diferenciados de salários e benefícios; cobrança dos sindicatos no cumprimento da legislação referente à participação dos empregados nos lucros das empresas; aumento do salário mínimo bem acima da inflação refletindo no piso salarial de diversas categorias; investimento das empresas na certificação e qualificação de pessoal, refletindo no aumento de salários; forte demanda do mercado por profissionais formados em cursos técnicos; reposição do pessoal aposentado da ArcelorMittal Tubarão (AMT), normalmente em final de faixa salarial, por profissionais jovens e em início de faixa.

Quanto aos maiores salários e benefícios do pessoal primarizado, respectivamente $13,89 \%$ e $134,26 \%$, foram neutralizados e superados pelo BDI cobrado pelas Contratadas, e que no nosso estudo é de $41,04 \%$ sobre os custos ou $29,1 \%$ sobre o faturamento (Tabela 2), e servem para cobrir as despesas com impostos $(16,8 \%)$ e administração central e lucro $(12,30 \%)$. 
Identificamos que os seguintes fatores foram determinantes na decisão de primarização da manutenção na AMT: redução de custos; perda de know-how; redução da capacidade ociosa; mitigação de riscos à imagem da empresa quanto à responsabilidade social, ambiental e passivos trabalhistas; queda na qualidade dos serviços e aumento no índice de acidentes e perdas materiais.

Não identificamos como presentes, no processo de primarização da AMT, os seguintes fatores: economia de escala; romper dependência unilateral e mitigar hold-up; redução da assimetria informacional e decisão judicial.

Este trabalho traz como principais contribuições: a sugestão da utilização da primarização como estratégia de redução de custos, tema que contrapõe a recente onda de terceirização e a apresentação de uma metodologia para identificar e mensurar os fatores que suportam a decisão de terceirização x primarização. Mostra que os impostos incidentes sobre a prestação de serviços, além do lucro e administração central e local, explicitados no BDI, fazem com que os custos da terceirização superem os da primarização.

Conclui que os ganhos reais de salários e os benefícios obtidos nas Convenções Coletivas de Trabalho, nos últimos dez anos, foram os responsáveis pelo aumento dos custos de serviços de terceiros e inviabilizaram a terceirização. Enquanto a variação do INPC no período de Nov/2002 a Out/2013 foi de 95,82\%, o acordo coletivo dos empregados das Contratadas, no mesmo período, foi de 133,41\% acrescidos de benefícios tais como: cestas básicas ou ticket alimentação, planos de saúde e odontológico, participação nos lucros, redução na jornada de trabalho, entre outros.

Apesar dos resultados obtidos e das conclusões apresentadas citamos como principais limitações do nosso trabalho: a) Os dados que comprovam o atingimento das metas estabelecidas devido à primarização são recentes e de um período inferior a doze meses, embora os resultados preliminares (9 meses) apontem para o acerto da decisão, conforme resultados apresentados pela Gerência Geral de Manutenção em Janeiro de 2014; b) Por tratar-se de um estudo de caso, portanto de uma amostra única, embora significativa, é possível que em outros segmentos e/ou dentro da própria siderurgia ocorram resultados diferentes. Sugerem-se, para futuras pesquisas, investigações sobre:

a) implantação da primarização em outros segmentos, a exemplo de (MAGALHÃES et al., 2011) na mineração e (SILVA, 2011) na celulose;

b) modelos de apoio à decisão da primarização, a exemplo do sugerido por (LINDERMANN; HANSEN, 2008) que propuseram o método multicriterial de apoio à decisão da terceirização ou primarização da manutenção com base em oito perspectivas;

c) influência do Ministério Público do Trabalho (MPT) e Sindicatos nas decisões das empresas públicas e privadas de terceirizarem ou primarizarem serviços bem como a aplicação de eventuais sanções como a da Suzano Papel e Celulose, que foi condenada a pagar 2 milhões de indenização por dano moral coletivo, ação impetrada pelo MPT da Bahia, pela terceirização ilegal de atividade fim da companhia, como produção de mudas, atividades de silvicultura, plantio e colheita de eucalipto (Exame, abril, 2013);

d) resultados da primarização no tocante: o maior comprometimento da mão de obra de terceiros que foi primarizada; à redução de taxas de acidente e absenteísmo; à redução de custos; ao aumento da produtividade, entre outros;

e) fatores negativos da primarização tais como aumento do corporativismo interno encobrindo ou mitigando eventuais desvios técnicos como retrabalhos e perdas materiais. 


\section{Referências}

AMORIM, W. A. C. Negociações coletivas no Brasil: a hora dos aumentos reais?

Informações FIPE, São Paulo, p. 32-37, out. 2010.

AZEVEDO, P. F. Integração vertical e barganha. 1996. 221 f. Tese (Doutorado) -

Programação de Pós-Graduação em Economia do Departamento de Economia FEA/USP, São Paulo (SP), 1996.

BEAUMONT, N. B.; SOHAL, A. Outsourcing in Australia. International Journal of Operations and Production Management, 2004.

BRUNI, A. L.; FAMÁ, R. Gestão de custos e formação de preços. 5a ed. São Paulo: Atlas, 2011.

CASTRO, A. S.; BIM, E. A. A viabilidade da "desterceirização" (outsourcing reverse): um estudo de caso sobre a reciclagem de componentes poluentes (baterias automotivas). In: CONGRESSO BRASILEIRO DE CUSTOS (CBC), 2007, João Pessoa (PB). Anais... João Pessoa: CBC, 2007.

DIEESE - Departamento Intersindical de Estatística e Estudos Socioeconômicos. Encargos sociais no Brasil: conceito, magnitude e reflexos no emprego. Convênio SE/MTE N ${ }^{\circ}$. 04/2003-DIEESE, abr. 2006.

DRAUZ, R. Re-insourcing as a manufacturing-strategic option during a crisis: cases from the automobile industry. Journal of Business Research, v. 67, p. 346-353, 2013.

FERRUZZI, M. A. et al. Razões da terceirização de serviços em empresas de médio e grande porte. Brazilian Business Review, v. 8, n. 4, p. 46-69, out./dez. 2011.

FIGUEIREDO JÚNIOR, A. M. F. A integração vertical parcial em uma operadora de saúde suplementar: um mecanismo estratégico anti hold-up. 2007. Dissertação (Mestrado em Ciências Contábeis) - Programa de Pós-Graduação da Fundação Capixaba de Pesquisa em Contabilidade, Economia e Finanças (FUCAPE), Vitória (ES), 2007.

GIOSA, L. A. Terceirização: uma abordagem estratégica. 5a ed. São Paulo: Pioneira Thomson, 2003.

GUTWALD, P. M. Strategic sourcing and technology supply chains. 1996. 93 f. Master Thesis, Massachusetts (MIT), 1996.

HAMEL, G.; PRAHALAD, C. K. Competing for the future. Harvard Business Review, p. 122, v. 72, n. 4, 1994.

A competência essencial da corporação. In: PORTER, M.;

MONTGOMERY, C. (Orgs.). Estratégia: a busca da vantagem competitiva. Rio de Janeiro: Campus, 1998.

HANSEN, D.R.; MOWEN, M. M. Gestão de custos: contabilidade e controle. São Paulo: Thomson Pioneira, 2003.

IBEC - Instituto Brasileiro de Engenharia de Custos. Conceito de BDI: orientação técnica no 01/2009/IBEC. Disponível em: 〈www.ibec.org.br>.

IBS - Instituto Brasileiro de Siderurgia. A indústria do aço no Brasil e os efeitos da crise.

Siderurgia em foco, n. 10, mar. 2009. Disponível em:

<http://www.acobrasil.org.br/siderurgiaemfoco/Siderurgia10.pdf〉. Acesso em: 19 mar. 2014.

Primarização como Estratégia de Redução de Custos: uma Metodologia para Identificar e Mensurar os... 
KAKABADSE, A.; KAKABADSE, N. Trends in outsourcing: contrasting USA and Europe. European Management Journal, v. 20, n. 2, p. 189-198, apr. 2002.

KLEIN, B. Contracts and incentives: the role of contract terms in assuring performance. In: WERIN, L.; WIJKANDER, H. (Eds.). Contract economics. Oxford: Blackwell, 1992.

Vertical integration as organizational ownership: the fisher body-General Motors relationship revisited. Journal of Law and Economics, v. 4, n. 1, p. 199-213, 1998.

KLEIN, P. G. The make-or-buy decision: lessons from empirical studies. CORI, Working Paper No. 04-07, 2004.

LAZZARIN, S. K. O custo da relação formal de emprego no Brasil. UNIRITTER, 2010.

LIMA, W. Indicadores de gestão: terceirização 2013. Disponível em:

<http://indicadoresdegestao.com/wp-content/uploads/2013/07/terceirizacao-2013.jpg>. Acesso em: 18 nov. 2013.

MAGALHÃES, Y. T. et al. Da terceirização à primarização: um estudo em uma mineradora de grande porte. In: SIMPÓSIO DE ENGENHARIA DE PRODUÇÃO, 16., 2009, Bauru.

Anais... Bauru: UNESP, 2009.

. et al. Primarização e relações de trabalho em uma empresa mineradora de Minas

Gerais. Sociedade, Contabilidade e Gestão, Rio de Janeiro, v. 6, n. 1, p. 104-119, jan./jun. 2011.

; SARAIVA, L. A. S.; CARVALHO NETO, A. Práticas gerenciais relacionadas à qualificação de trabalhadores terceirizados: um estudo de caso no setor de mineração. Organizações \& Sociedade, Salvador (BA), v. 18, n. 57, p. 227-244, abr./jun. 2011.

MARTINS,E. Contabilidade de Custos. 9a ed. São Paulo: Atlas, 2003.

; ROCHA, W. Métodos de custeio comparados: custos e margens analisados sob diferentes perspectivas. São Paulo: Atlas, 2010.

MIRSHAWKA, V.; OLMEDO, N. L. Manutenção: combate aos custos da não-eficácia: a vez do Brasil. São Paulo: Makron Books, 1993.

NASCIF, J.; DORIGO, L. C. Manutenção orientada para resultados. Rio de Janeiro: Qualitymark, 2010.

PALMA, P. S. S. Processo de internalização das actividades de MPS de via/geotecnia do Centro de Manutenção de Lisboa. 2012. Dissertação (Mestrado em Engenharia Civil) Instituto Superior de Engenharia de Lisboa (ISEL), Lisboa (POR), 2012.

PASTORE, J. Encargos sociais: implicações para o salário, emprego e competitividade. São Paulo: LTr, 2001.

PERÚCIA, A.; BALESTRIN, A.; VERSCHOORE, J. R. Coordenação das atividades produtivas na indústria brasileira de jogos eletrônicos: hierarquia, mercado ou aliança. Produção (Unisinos), São Leopoldo (RS), v. 21, n. 1, p. 64-75, jan./mar. 2011.

PORTER, M. E. Estratégia competitiva. Rio de Janeiro: Campus, 1986.

Vantagem competitiva: criando e sustentando um desempenho superior. 15a ed. Rio de Janeiro: Campus, 1989.

Competição: estratégias competitivas essenciais. 8a ed. Rio de Janeiro: Campus, 1999. 
PURCELL, K.; PURCELL, J. In-sourcing, outsourcing and the growth of contingent labour as evidence of flexible employment strategies. European Journal of work and organizational Psychology, London, v. 7, n. 1, p. 39-59, mar. 1998.

QUEIROZ, C. A. R. Manual de terceirização. 10a ed. São Paulo: STS, 2004.

QUINN, J. B.; HILMER, F. G. Strategic outsourcing. Sloan Management Review, v. 35, n. 4, p. 43, 1994.

SARAIVA, L. A. S.; SILVA, M. A.; MAGALHÃES, Y. T. Terceirizar ou primarizar a manutenção? A tomada de decisão em uma mineradora. In: ENCONTRO NACIONAL DE ENGENHARIA DE PRODUÇÃO, 29.1 2009, Salvador (BA). Anais... Salvador: Abepro, 2009

SHANK, J. K.; GOVINDARAJAN, V. A revolução dos custos. Rio de Janeiro: Campus, 1997.

SILVA, J. F. Comparativo entre processos florestais terceirizados e primarizados. 2011. Dissertação (Mestrado) - Escola Superior de Agricultura "Luiz de Queiroz", Piracicaba (SP), 2011.

SINDIFER - Sindicato das Indústrias Metalúrgicas e de Material Elétrico do Estado do Espírito Santo. 2013. Disponível em: 〈www.sindiferes.com.br>.

SINDIMETAL/ES - Sindicato dos Trabalhadores nas Indústrias Metalúrgicas, Mecânicas, de Material Elétrico e Eletrônico no Estado do Espírito Santo. 2013. Disponível em:

<http://sindimetal.es.org.br/main.asp?link=odownload\&id=398\#[AbreEmDIV]ajax.asp?link= downloads\&cat=Acordos e Convenções $>$. Acesso em: 01 nov. 2013.

SOUTES, D. O. Custo Total de Propriedade (TCO): é importante? Para quem? Ciências Sociais em Revista, v. 7, n. 13, p. 83-105, 2007.

TREACY, M.; WIERSEMA, F. The discipline of market leaders: choose your customers, narrow your focus, dominate your market. USA: Addison-Wesley, 1995

WILLIAMSON, O. E. Markets and hierarchies: analysis and Antitrust Implications. New York: The Free Press, 1975.

The economic institutions of capitalism: firms, markets, relational contracting. New York: The Free Press, 1985.

YIN, R. K. Estudo de caso: planejamento e métodos. 4a d. Porto Alegre: Bookman, 2010. 